\title{
Salt from the Sea
}

\author{
Some Details of a Little Known California Industry
}

By Arthur L. Dahl



S ALT is one of our food requisites, and though a seasoning what we way in miss its presence as much as any other ingredient. Stock will travel for many miles to reach a "salt lick," and the judicious use of salt is one of the methods employed by stock men to guide and control the movements of cattle on the big IVestern

In addition to its use for culinary and food purposes, culinary and food purposes, salt is largely employed in
the meat-packing, fish-cur-

ing, ice-cream making and other industries to preserve food from deterioration. It enters into the re frigeration process, and it is employed in the chlorination of gold and other metals. Salt helps to form glaze on pottery, and it is used in enameling and pipe works, and for curing hides. Many chemical industries use salt brine in the preparation of chemicals having a soda base, such as soda ash, and caustic soda. Altogether, salt has many uses, and the United States an nually consumes more than $50,000,000$ barrels.

No country in the world has more aluundant or more widely distributed salt resources than the United States, for salt is found, in some form, in all parts of the country, and the supply seems inexhaustible of the country, and the supply seems inexhaustible. Many want of markets, as our domestic demands and a constantly growing export trade is easily supplied from the salt works already in operation, and most of these can be greatly expanded if the occasion requires.

Our salt supplies come from three different sourcesthe mining of rock salt in such states as Michigan, Ohio, Kansas, and others, the making of salt from the same and many other the same and many other Eastern and Central States,
from the evaporation of from the evaporation of ocean water on the Pacific Coast, and at Syracuse, N. Y. Since the average value per barrel of all salt marketed in this country is in the neighborhood of forty cents, it is apparent that any method used in its man ufacture must be exceedingly economical to be successful For this reason posits of salt remain undeveloped because the compe. tition from existing salt works is too keen.

On the coast of California there has been developed in recent years quite an extensive industry in the manufacture of ordinary salt, or sodium chloride, from sea water. California ranks fifth in salt production, practically all of which comes from the sea. Aside

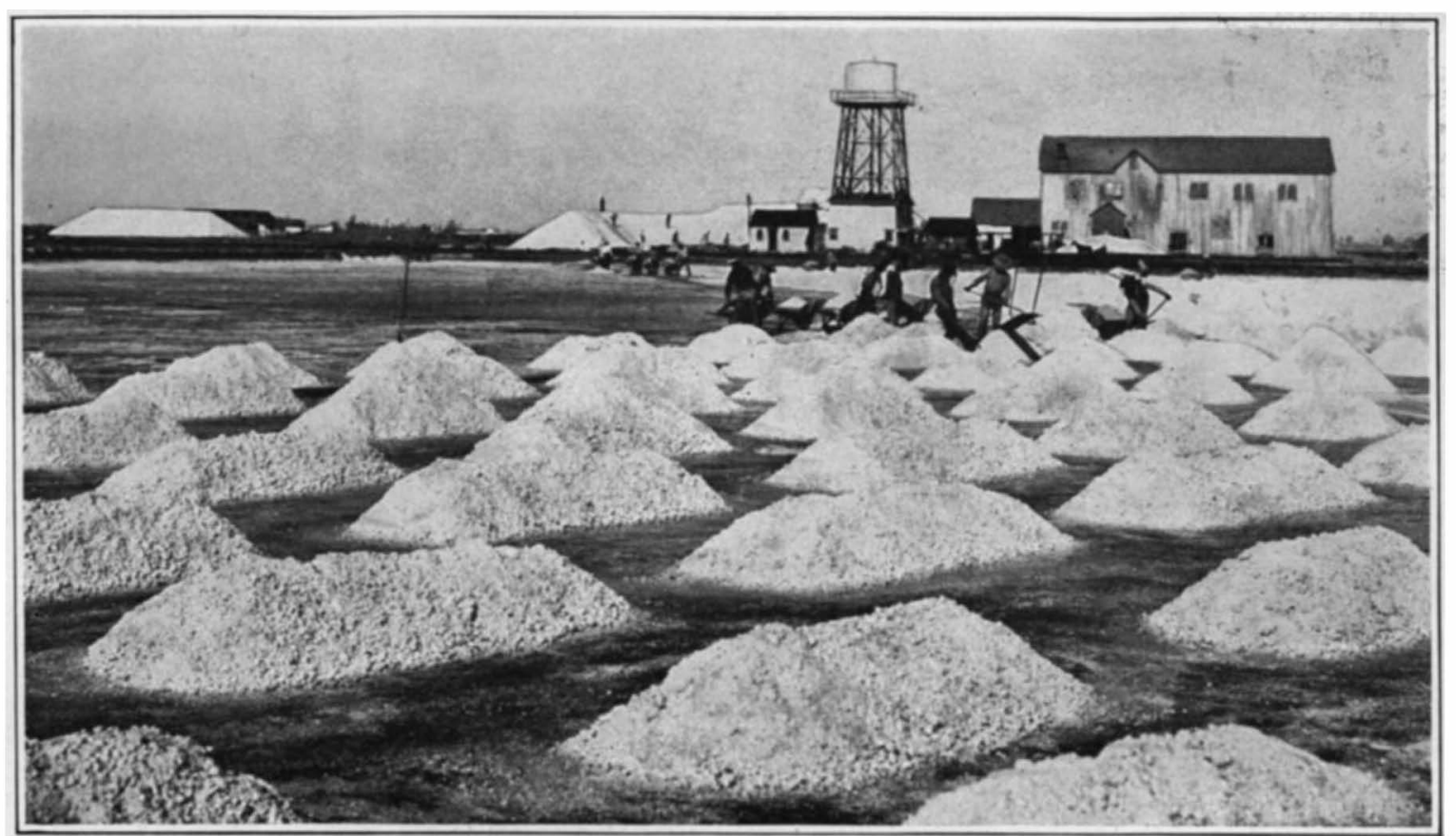

Removing the raw salt from the crystallizing ponds
3. Salt pyramids piled for salt from ocean water to How salt is recovered from the waters of the Pacific

from the salt works on Great Salt Lake, in Utah, and at Syracuse, N. Y., practically the only solar salt plants in the United States are in California. On San Francisco Bay there are numbers of these solar plants, and others operate in southern California, near Long Beach and San Diego.

Ocean water contains, on an average, 3.77 per cent of salt, although the salinity of ocean water varies in different localities, owing to evaporation and othe causes. For instance, the waters of the Pacific in the vicinity of San Diego contain an average of 4 per cent of salt, while that farther north is less.

In the manufacture of salt by the solar. process natural forces are utilized wherever possible, for it is only by this means that the business can be made profitable. At each plant an average of over 1,000 acres of low-lying land is utilized as salt ponds. The land is divided off into a number of ponds, each surrounded by earth dams or dikes, and connected with one another by flood gates. If the conditions will per mit, the water is let into the various ponds by the force of the tide, and where pumping is necessary, wind mills furnish the power.

furnter the pow in on the plant constantly, but most of the bay plants introduce new water only at high tide, and

the evaporating ponds.

$m$ one pond to another and allowed to remain in each for a given period, until gradually the water becomes more and more saline and this concentrated water is then let into the crystallizing ponds when crystals of salt have begun to form. At søme plants when the pickle in the salt ponds has reached a strength of $29 \mathrm{de}$ grees B., the bittern with some salt in it is run into other ponds, where it evaporates until a concentration of 32 degrees $B$. is reached, when the mother liquid is allowed to go to waste.

On a general average, a plant will provide about ten evaporating ponds for one crystallizing pond, and dur ing the salt season it is the aim of the management to keep all parts of the plant running in unison, so that a maximum of salt can be har(Continued on page 159) 
Salt from the Sea (Continued from page 150) vested profitably from the sea at all times. It is not possible to utilize gravity to and many of the bay plants have installed a great number of small wind mills which pump the water from one pond to another. Usually this pumping serves to get the water into the highest ponds, from which gravity will convey it through the intermediate ponds into the crystallizing tanks Since strong trade winds blow regularly during most of the summer months at San Francisco, these wind mills supply ample power for pumping, although electric motors or gasline engines are used for emergency power.

Harvesting takes place from the crystallizing ponds, and the salt deposits are shoveled into wheelbarrows or tram cars and conveyed to the drying piles. The larger plants have small railroads, with electric engines to pull the trains of salt cars, lut most of the smaller plants harrest by hand. The salt is not taken from the bottom of the pond, since the floor is usually made of mud, and this lower strata is left until the end of the season, when it is harvested separately and used for stock or in the manufacture of ice cream.

The salt when harrested is of a pinkish hue and still has considerable of the mother licuicl remaining, and it is piled in huge pyramids or staclss to dry out hefore being milled. When made into small piles the crust sometimes becomes so hard that it is necessary to use a cross-cut saw to break it up into chunks. When made into larger piles, it is more easily handled. Bucket elevators, endless belts and other mechanical conveyors are used to transport the salt to and from the storage piles.

Crude sea salt contains considerable adhering pickle or bittern and dirt of various kinds, and washing is accomplished in various ways. The salt may be dumped into a hopper and flushed with hot brine, or it is sometimes sprayed with cold ocean water taken from the hay. Usually the brine employed in the washing process is concentrated to complete saturation so that very little salt is dissolved in the washing. After this first washing, the salt passes between rolls which crush it into "half-ground salt," and "threequarters ground salt." It then goes to vats filled with artificial brine made from vats filled with artificial brine made from containing no mother liquid salts. When washed in this solution the salt is stacked in heaps to drain. If intended for the coarser uses of trade the salt is sacked in its present condition, but if intended for further refining the salt goes to vats which lead to centrifugal machines by which lead to centrifugal adhering water is removed. It which all adhering water is removed. It is then conveyed to driers, marle up of coils and provided with fans that pump warm air through. When dried, the salt is passed through heavy rollers which crush it. into granular or powder form, and it is then sifted and graded for fineand it is the

The amount of salt harvested from sea water averages from four to six inches in the crystallizing ponds, and at many of the plants two or more harvests can be secured each season. California produces about a million and a half barrels of sea salt per annum, which is sold throughout the Pacitic Coast and to some extent in the Eastern States. In the interior of the state are vast deposits of salines containing a number of valuable products, including common salt, and some of these deposits are being worked for their borax, potash and other contents.

\section{Solid Fuel for the Gas Engine}

Continued from page 151)

which is thus at all times instantly sup plied with the exact amount of moisture necessary to meet the demands of the
instant.
This producer is designed by Mr. A. I alusha of New York, and represents the ruit of many years' specialization in this field. In regular service it has shown an economic efficiency as high as 87 cent, at full load; under arerage conditions it will not fall far short of heat units in the fuel, in a clean, rich
heat cool units in the fuel, in a clean, rich, cal available for use in the produce entains 12,500 British thermal units per ound; this producer will deliver easily 10,000 of these in the gas. The modern gas engine will deliver at full load one rake horsepower on this fuel value; the net result is then a fuel consumption of but one pound of coal per brake-horsepower-hour.

Another feature of the new producer hat is usually questioned by prospective purchasers, and that only receives full credit after long use has demonstrated it, is the ability of the apparatus to go ight on delivering its full rated capacity while the ash-pit is open for cleaning. For those who are not acquainted with the merits or demerits of the ordinary producer it may not be out of place to producer it may not be out of place to state that there is no smoke and no chimney. The space required is less than that necessary for a steam plant. $\mathrm{Al}$ lowing for economical intermittent serv ce, the claim is made that the stand-by oss is a bare one-seventh that suffered in the use of steam. A very notalle point that the range of fuel is almost limitless. The use of a fairly decent grade f coal is of course recommended; but me manufacturers of the producer are most enthusiastic in their statements that anything that will burn, and some things that won't burn, may be used in the producer to generate gas. Clean water is not at all necessary, since steam is not used in working parts but is merely supplied as an ingredient of the gas.

This producer is designed to replace the steam engine in the ordinary power plant of moderate or moderately large apacity. The makers of the engine used during the war in our submarine chasers re operating their factory with a procent, the producer supplying gas to one of the company's own engines. A prominent maker of natural-gas engines for stationary use is installing the producer as standard equipment and finds it cheaper in supplying both heat and power in chemical plant, and in ice plants the producer is in satisfactory service. In the latter instance, a production of ten tons of ice per ton of coal burned under boilrs has been replaced by a production of thirty tons per ton of coal burned in the producer. This particular producer is eminently suitable for marine use, and was in a vessel just arrived from the ion. It is also in wide use in municipal power plants in small and medium-sized towns and cities.

Modern engineering skill often bring about a situation where what appears to the layman to be a roundabout procedre is the most efficient and the cheapest. ducer is a case in point. Within very wide limits the statement is a safe one that a given amount of coal converted into as in this producer and used in an internal-combustion engine will yield a much greater return in power, at lowe cost of operation and lower initial cost of installation, and with increased reliability of operation, than if it were employed under a boiler to convert water into steam for direct application.

Keeping Check on Factory Air Continued from page 151)

from the alkalinity which disappears, hat definitely absorbed by the carbonic cid.

In order to find the carbon monoxide
with this apparatus, use is made of the

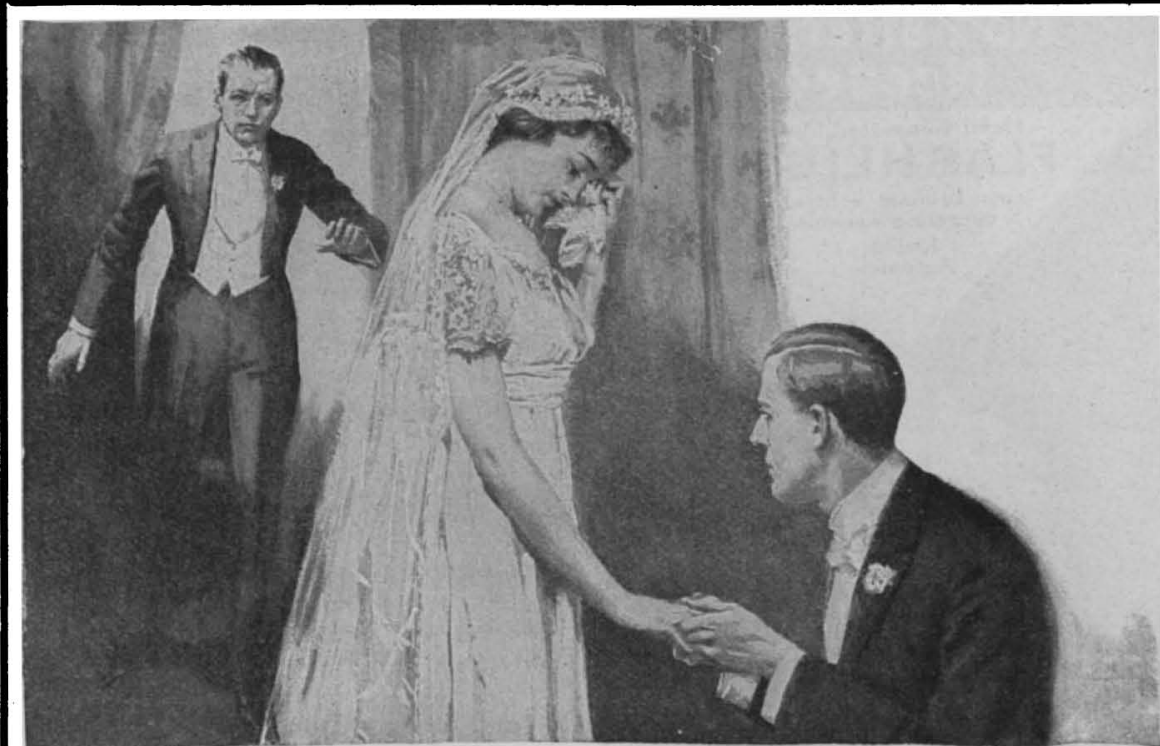

\section{If This Happened on Your Wedding Night}

She had gone to change into her traveling dress. A few moments later he found her in her room-the woman he had just made his wife-and his best friend-What would you have done? What did he do? Find out from the story by



For years now you have heard of 0 . Henry-you have read these advertisements and thought that some day you would own a set for yourself. But you have put off the sending from month to month. The time for that is gone. Now - today - you must order your set of 0 . Henry to get the low price and the Oppenheim FREE!

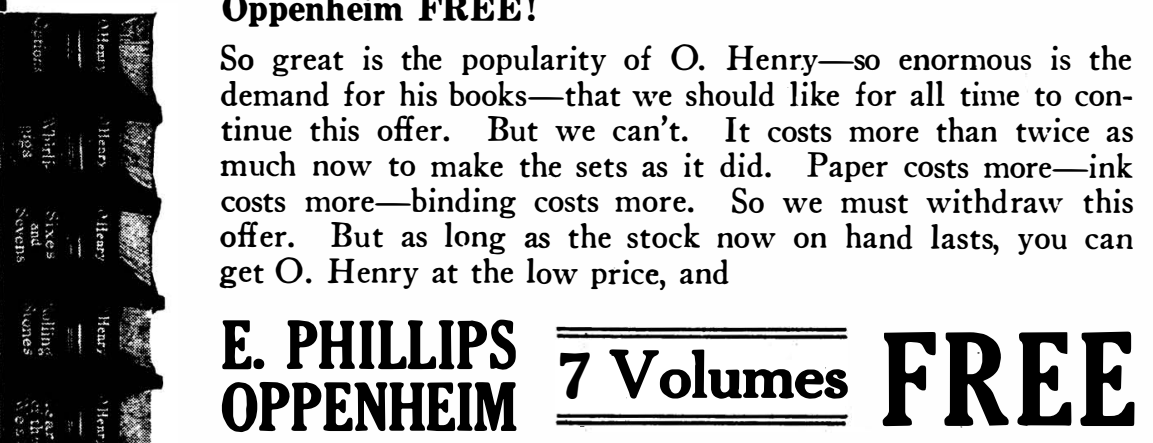

No other writer ever knew so much of the secret history of Europe. No other writer ever understood so well the hidden forces-the secret intrigues-the startling accidents-the sudden deaths-that have kep Europe in turmoil for the past generation. He was looked upon as the most dangerous man in England. He was marked down by Germany for private execution, because he knew too m
and intrigues; he suspected too many of her designs.

Fighting-scheming - plotting-mystery-love-adventure-all these are in his stories-and all his marvelous genius is in the telling of them. He makes them so real that you forget everything about you in the joy of them. He lets you into secrets that take your breath away. He you the real inner workings of European diplomacy. He holds you enthralled with

\section{Your Last Chance to Get a FREE SET}

This is the last edition of $\mathrm{E}$. Phillips Oppenheim

we can get at the special price which permits of

our giving them free with $O$. Henry. When

this one edition is gone (and there are com-

paratively few sets now left) you will
able to get E. Phillips Oppenheim's won-

able to get E. Phillips Oppenheim's won-

of $\$ 1.75$ or more a volume.

Now, while you can, get the O. Henry
at the low price with E. Phillips

at the low price with E. Phillips

Oppenheim five you such a chance.
can, we gons it! Cut the coupon.

Send it TODAY!

THE REVIEW OF REVIEWS ca

30 Irving Place
New York City

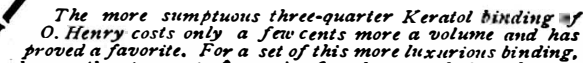

